Research Article

\title{
Aerodynamic Characteristics Evaluation of a Cable-Stayed Bridge Section with a New-Type Hybrid Fairing
}

\author{
Hoyeop Lee $\mathbb{D}^{1}$ and Jiho Moon $\mathbb{D}^{2}$ \\ ${ }^{1}$ Kepco Research Institute, Yuseong-Gu, Daejeon 34056, Republic of Korea \\ ${ }^{2}$ Dept. of Civil Engineering (Dept. of Integrated Energy \& Infra System), Kangwon National University, Chuncheon-si, \\ Gangwon-do 24341, Republic of Korea
}

Correspondence should be addressed to Jiho Moon; jmoon1979@gmail.com

Received 7 June 2020; Revised 23 March 2021; Accepted 13 May 2021; Published 25 May 2021

Academic Editor: M.Z. Naser

Copyright $(\subset) 2021$ Hoyeop Lee and Jiho Moon. This is an open access article distributed under the Creative Commons Attribution License, which permits unrestricted use, distribution, and reproduction in any medium, provided the original work is properly cited.

In this study, new-type hybrid faring is suggested to improve the aerodynamic performance of the long-span cable-stayed bridge. The proposed fairing is developed by applying the concept of the multibox section to the normal faring. The proposed faring has void regions inside the faring so that wind passes through the gaps in the faring. As a result, the wind flow is changed and the forces to the bridge section are reduced. The efficiency of the proposed faring was verified by a series of wind tunnel test. From the test result, it can be found that aerodynamic performances, such as drag force and flutter resistance, are enhanced.

\section{Introduction}

Aerodynamic forces are the main design load for the longspan cable-stayed bridge, and several studies have been conducted to improve the aerodynamic performance of such bridges. One of the effective methods to improve the aerodynamic performance of the bridge is to change the bridge section shape. There are three different approaches to changing the bridge section shape. The first method is direct modification of the section dimensions, such as the height, width, and slope of the section change, or relocation of the girder and barrier. The second method is the installation of additional attachments, such as fairing and flap, to the existing bridge section. The third method is the development of a new concept bridge section. An example of the new concept bridge section to improve the aerodynamic performance is the multibox section. Stonecutters bridge (main $\operatorname{span}=1,018 \mathrm{~m}$ ) and Messina bridges (main $\operatorname{span}=3,300 \mathrm{~m}$ ) are designed with twin and triple-box sections, respectively. By applying the multibox section, the winds pass through the void region between the boxes, and the aerodynamic performance can be improved. Studies to improve the aerodynamic characteristics with new ideas and technologies have been conducted by previous researchers $[1,2]$.

Among these methods, the focus of this study was made on the proposal of new-type hybrid faring by adding the concept of multibox section to the normal faring, as shown in Figure 1.

The proposed hybrid fairing is basically an additional attachment, and it is used for an existing bridge to improve the aerodynamic performance. In this study, the target bridge section is a single box section. By applying the concept of the multibox section to the normal fairing, void regions inside the faring were provided. As a result, winds are passed through a void in the fairing and the wind flow of the section is changed. To evaluate the performance of the proposed hybrid fairing, static and dynamic wind tunnel tests for the bridge deck were conducted. The main parameter is the wind penetration ratio, which is defined as the void area to the total area of the fairing. Wind penetration ratios of $0 \%, 25 \%$, and $50 \%$ were selected for the tests, where $0 \%$ wind penetration ratio fairing represents the normal fairing without the void. The tests show that the aerodynamic characteristics of the section were improved by applying the proposed new-type hybrid fairing. 


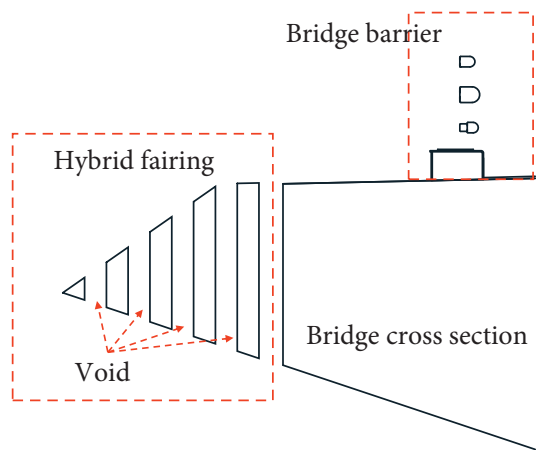

FIgURE 1: Concept of the proposed new-type hybrid fairing.

\section{Previous Researches and the Proposed New- Type Hybrid Fairing}

2.1. Previous Researches. The cross section of the bridge is an important parameter that affects the aerodynamic characteristics of the long-span cable-stayed bridge. The static wind load is calculated by using the aerodynamic drag coefficient, which is determined by the section shape of the bridge. The vortex characteristic is also closely related to the section shape of the bridge. The Strouhal number, which varies depending on the section shape, affects the vortex-induced vibration speed and amplitude. Furthermore, the section shape affects the flutter speed. Vortex-induced vibration is motions induced on structures interacting with an external wind flow and it occurs when the vortex shedding and the structural vibration synchronize at common frequency. Flutter is one of the aeroelastic instabilities, and it can lead the collapse of the bridge. The flutter occurs when the total damping of the structure becomes zero by the structurewind flow interaction. As a result, the displacement (or rotation) diverges. In consequence, several previous studies have been conducted for the effect of the cross section shape of the bridge on the aerodynamic characteristics, such as the static wind load, vortex-induced vibration, and flutter.

As mentioned before, there are three different methods to change the bridge cross section to enhance the aerodynamic performance, as shown in Figures 2(a)-2(c).

The first method is direct modification of the dimensions of the ordinary section. The second method is the use of attachments to the section. The third method is to develop a new concept section. In the case of the first method, the following recent research efforts have been conducted. Larsen and Wall [3] investigated the cross section shape of the box girder bridge to prevent the vortex shedding response. They reported that when the angle of the lower face is less than $16^{\circ}$, the vortex shedding response is reduced. Fransos and Bruno [4] studied the aerodynamic characteristics of the trapezoidal box girder section by using computational fluid dynamics (CFD) analysis. The analysis results showed that the aerodynamic behavior is affected by the lower corner degree of sharpness of the trapezoidal box section. Lee et al. [5] studied the effect of the edge-box girder section shape on the static wind load coefficients through a wind tunnel test and CFD analysis. From the results, the optimum slope angle of the section was proposed. Also,
Daito et al. [6] conducted similar research for the edge-box girder section focusing on the dynamic characteristics.

When the shape modification of the section is difficult, additional aerodynamic attachments are used to improve the aerodynamic performance of the bridge. Although these attachments are nonstructural members, they change the wind flow near the bridge section. Fairings, flaps, edge plates, side plates, baffle plates, and gratings are used as additional attachments [7]. Among these attachments, the fairing is widely used, since it is easy to handle. A triangular shape fairing is generally used since it segregates the streamline near the section, and several studies have been conducted for it. Nagao et al. [8] investigated the effect of the size of the triangular shape fairing on the aerodynamic behavior of the box girder. Similar studies were performed for the edge-box girder and trapezoidal box girder by Sukamta et al. [9] and Hanque et al. [10], respectively. Also, there are several types of fairing, such as the half-circular and the propeller type. The research into these fairings has been conducted by Tanaka et al. [11].

Since the mid-2000s, to overcome the length limit of the cable-stayed bridge, the multi-section was proposed [Refer Figure $2(\mathrm{c})$ ]. The multi-section has large $B / D$ ratio compared to the single box section, where $\mathrm{B}$ and $D$ are the width and depth of the section, respectively. Generally, with increasing $\mathrm{B} / D$ ratio, aerodynamic lift force and moment are increased. In the case of the multi-section, there are void regions between the sections where the wind can pass through, as shown in Figure 2(c). Then, aerodynamic lift force and moment can be reduced, without changing the $\mathrm{B} / D$ ratio $[12,13]$.

The multisection is called by several different names as the slotted box girder [14], flat box girder [15], tandem box [16], twin box [17], and two separated steel boxes [18]. Sometimes, the multisection consists of more than two separated boxes. For example, Messina bridge has a triple deck system, and Diana and Fiammenghi [19] conducted a wind tunnel test for it. Recently, Wang and Dragomirescu [20] proposed a fourth deck system, and Zasso et al. [21] investigated the effect of the number of boxes (from one to three) in multisection on the aerodynamic behavior.

In addition to the methods mentioned above, several challenging studies have been conducted to improve the aerodynamic performance of the bridge. For example, $\mathrm{Li}$ et al. [22] and Gouder et al. [23] proposed an active wind load feedback control method by sensors and actuator to change the wind flow near the bridge and improve the flutter resistance.

2.2. The Proposed New-Type Hybrid Fairing. As a part of such challenging studies mentioned in Section 2.1, a new-type hybrid fairing is proposed by mixing the concept of normal fairing and multi-section, as shown in Figure 1. Basically, the proposed attachment is the fairing, and the focus is made on the improvement of the static and dynamic aerodynamic performance of the normal fairing, by adding the advantage of the multisection. The performance of the proposed newtype hybrid fairing was evaluated by a series of wind tunnel 


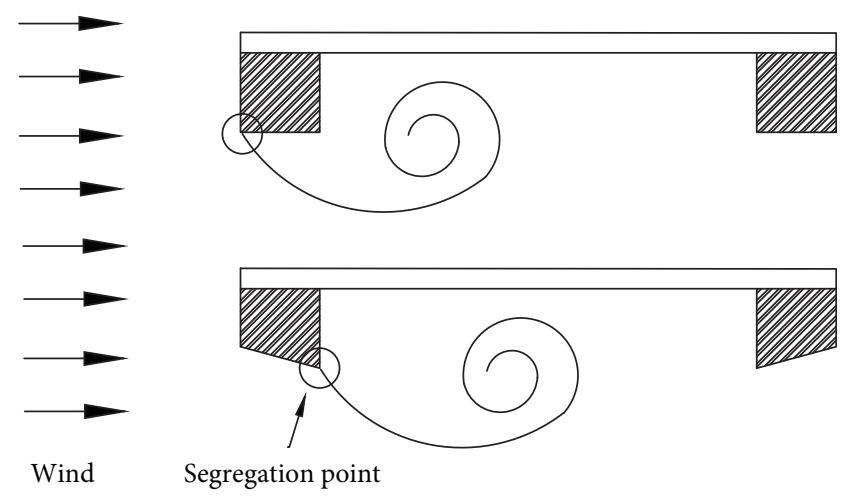

(a)

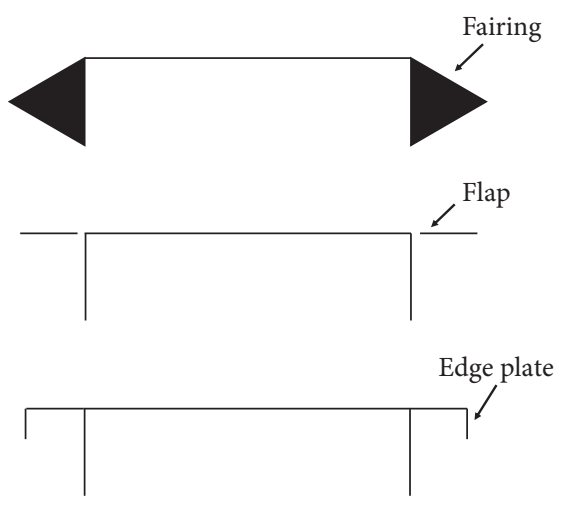

(b)

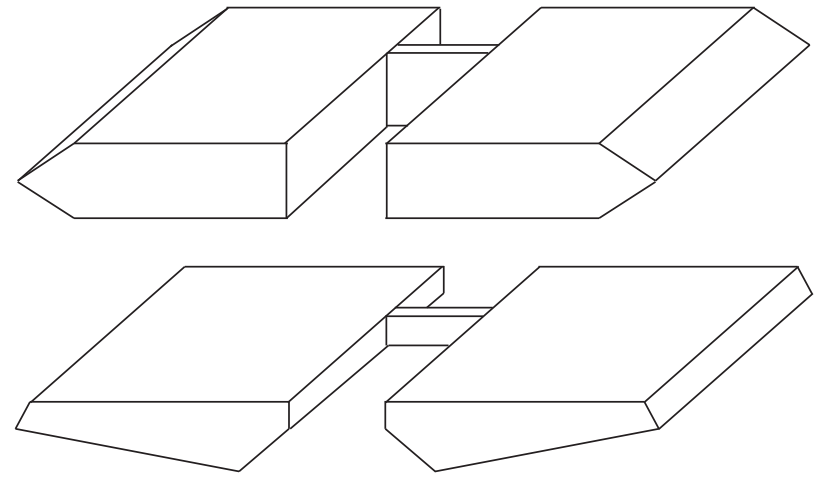

(c)

FIGURE 2: Methods to improve the aerodynamic performance: (a) shape change, (b) additional attachment, and (c) multisection.

tests. The main test parameter is the wind penetration ratio, which is defined as the ratio of void area to total area of the fairing. Thus, the wind penetration ratio (WPR) is defined as

$$
\text { wind penetration ratio }(\mathrm{WPR}, \%)=\frac{(\text { void area })}{(\text { total area })} \times 100 \text {, }
$$

where the definition of the void and the total area of the fairing is shown in Figure 3.

By applying the void region to the normal fairing, it is expected that the drag force is reduced, due to the wind that is passing through the void region. Also, the increase of flutter speed is expected by reducing the pressure difference between the upper and lower parts of the bridge section.

\section{Wind Tunnel Test}

3.1. Test Bridge and Section. To verify the performance of the proposed fairing, static and dynamic wind tunnel tests were conducted. Figure 4(a) shows the target cable-stayed bridge where the main span of the bridge is $1,200 \mathrm{~m}$. Figure $4(\mathrm{~b})$ shows the cross section of the bridge. The single steel box section is considered where the total width and the depth of the section are $29 \mathrm{~m}$ and $4 \mathrm{~m}$, respectively, with 4 lanes. The width of the steel box section is $24.8 \mathrm{~m}$. At the left and right ends of the steel box, the triangular shape fairing with the width of $2.1 \mathrm{~m}$ is installed, as shown in Figure 4(b). Thus, the total width is equal to $29 \mathrm{~m}$.
In this study, the main parameter is the wind penetration ratios (WPR) and WPR of $0 \%$ (the normal fairing), $25 \%$, and $50 \%$ were considered. With increasing WPR, the effect of WPR on the aerodynamic characteristics may be improved. However, the structural rigidity is decreased. Thus, the maximum WPR was set as $50 \%$ so that the fairing can have enough structural rigidity to handle. $2 \mathrm{D}$ wind tunnel test was conducted for each case. A 1:70 scale model was used for the tests. Figure 5 shows the example of the test model used in this study.

3.2. Wind Tunnel Test and Parameters. The wind tunnel test is often used to investigate the effect of wind moving past the structure. The test model is mounted in the middle of the wind tunnel and it instrumented with several sensors to measure the response of the test model. The static wind tunnel test, where the test model is fixed with load cells at their ends, is used to investigate the wind force acting on the model. The vortex-induced vibration and flutter response can be investigated by using the dynamic wind tunnel test, where the test model is mounted on the spring support system.

2D wind tunnel test has been widely used to investigate the aerodynamic behavior of the bridge as an alternative of full 3D wind tunnel test. In the case of 2D wind tunnel test, mass, stiffness, frequency, and damping ratio of whole model (3D model) are firstly determined. Then, these factors are 


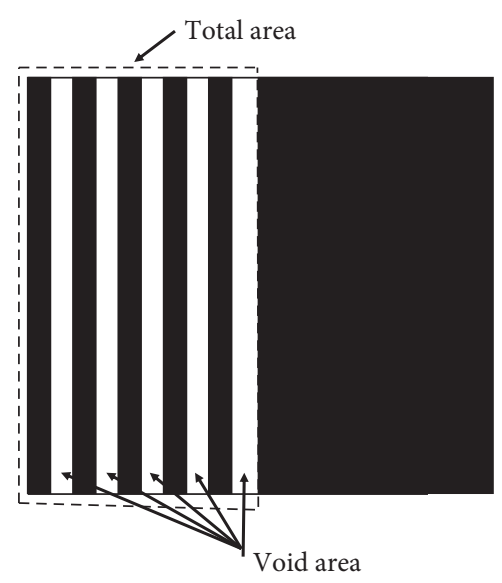

(a)

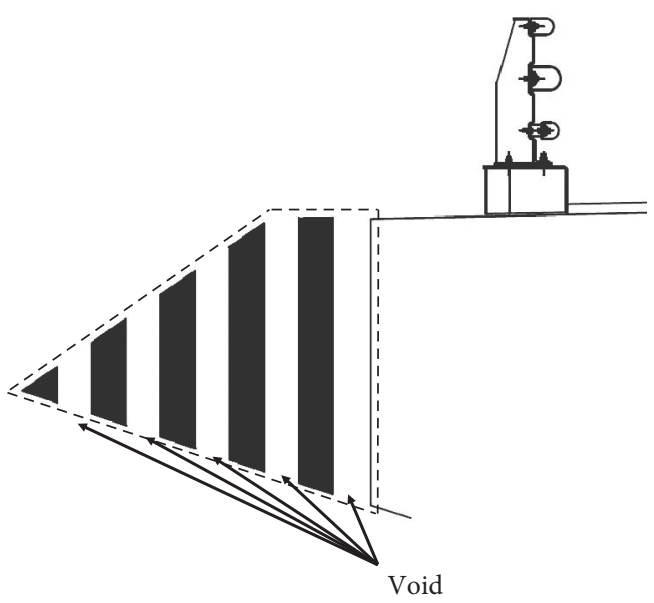

(b)

FIgURE 3: Definition of the wind penetration ratio: (a) plan view and (b) section view.

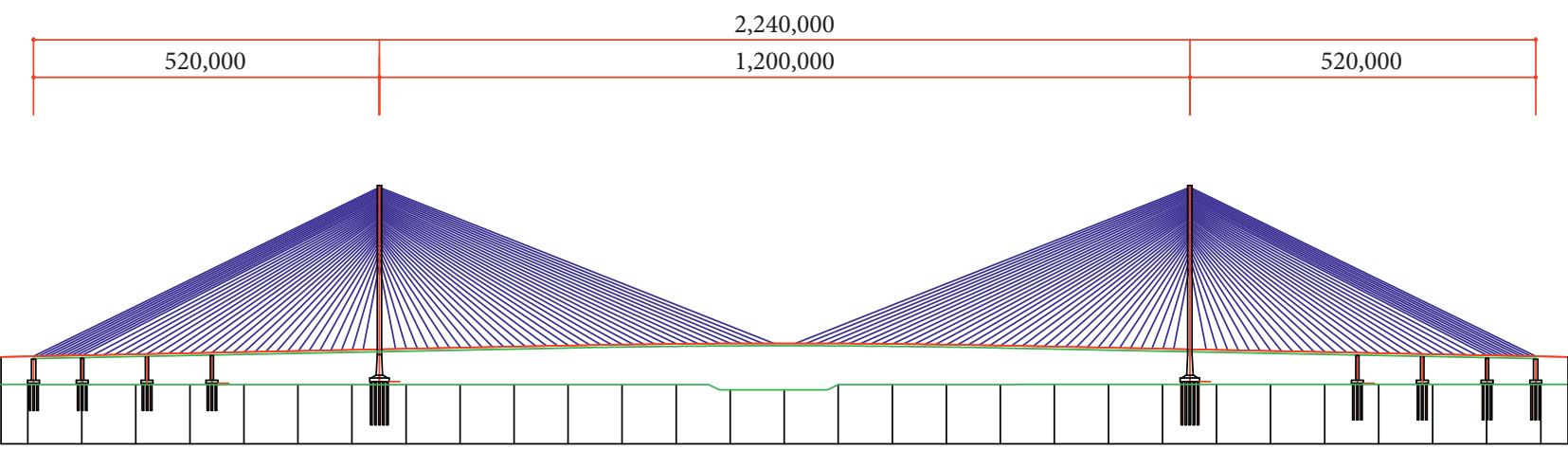

(a)
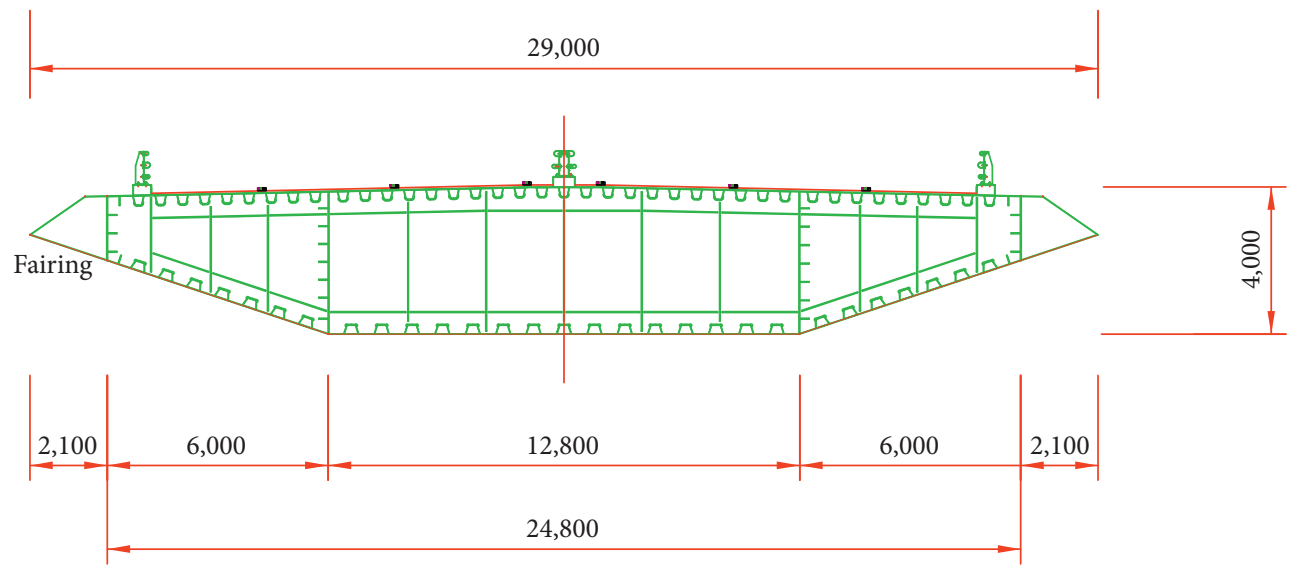

(b)

FIgURE 4: Target bridge and section (unit: $\mathrm{mm}$ ): (a) dimensions of the bridge and (b) dimensions of the cross section.

considered in $2 \mathrm{D}$ wind tunnel test setup to reflect $3 \mathrm{D}$ bridge behavior.

Table 1 shows the unscaled properties of original bridge and scaled properties for the wind tunnel test. The unscaled vertical and torsional frequencies are 0.1947 and $0.5044 \mathrm{~Hz}$, respectively. Thus, the ratio of vertical frequency to torsional frequency, $\mathrm{V} / \mathrm{T}$ ratio, is 2.5910 . The unscaled mass per unit length of the section is $17,906 \mathrm{~kg} / \mathrm{m}$. The unscaled moment of inertia is equal to $898.79 \mathrm{kN} / \mathrm{g} \cdot \mathrm{m}^{2}$. The damping ratio is determined as $0.4 \%$. These values were scaled for the wind tunnel test with 95\% accuracy, as shown in Table 1.

The wind tunnel in Korea University was used for the test, where the size of wind tunnel is $1.0 \mathrm{~m} \times 0.8 \mathrm{~m}$ (Width $\times$ Height). Figure 6 shows the test setup for the wind tunnel test. In the case of the static wind tunnel test, the drag, lift forces, and moment are measured from the 3- 


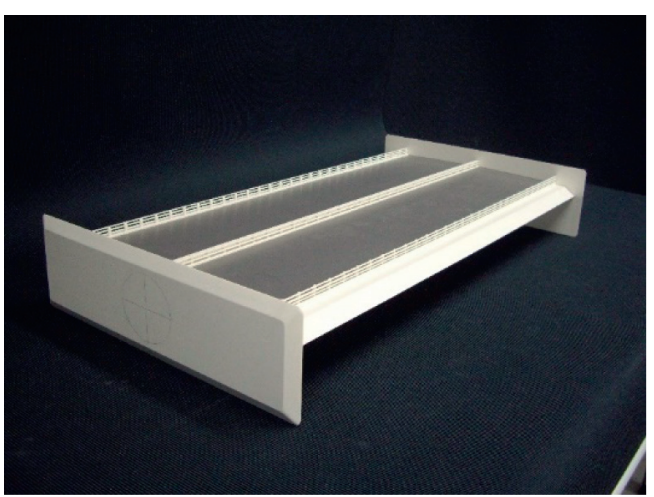

(a)

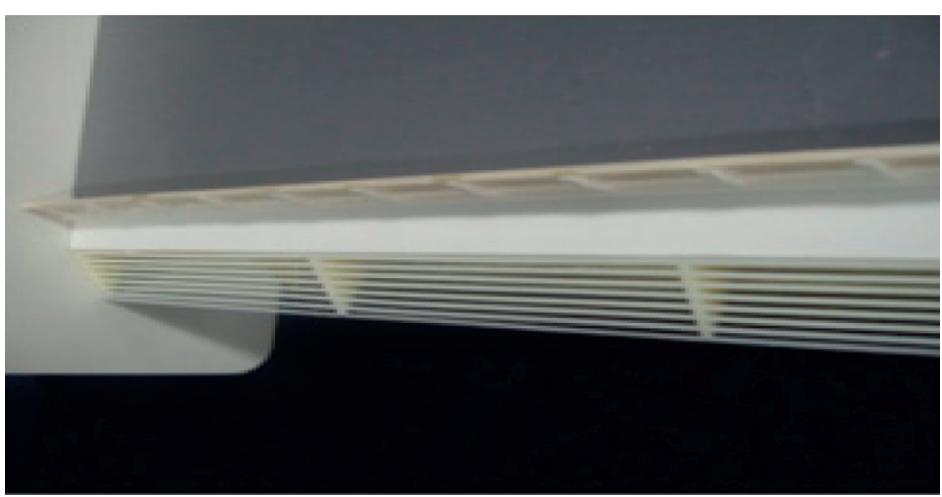

(b)

FIgure 5: Test model: (a) 1:70 scaled model with the normal fairing and (b) model with 50\% WPR fairing.

TABLE 1: Parameters of the scaled model cross section.

\begin{tabular}{lcc}
\hline Title & Value & Scaled value \\
\hline Vertical frequency & $0.1947 \mathrm{~Hz}$ & $1.6290 \mathrm{~Hz}$ \\
Torsional frequency & $0.5044 \mathrm{~Hz}$ & $4.2201 \mathrm{~Hz}$ \\
V/T ratio & 2.5910 & 2.5910 \\
Mass per unit length & $17,906 \mathrm{~kg} / \mathrm{m}$ & $3.1061 \mathrm{~kg} / \mathrm{m}$ \\
Mass moment of inertia & $898.79 \mathrm{kN} / \mathrm{g} \cdot \mathrm{m}^{2}$ & $0.03182 \mathrm{kN} / \mathrm{g} \cdot \mathrm{m}^{2}$ \\
Damping ratio (vertical and torsional) & $0.4 \%$ & $0.4 \%$ \\
\hline
\end{tabular}

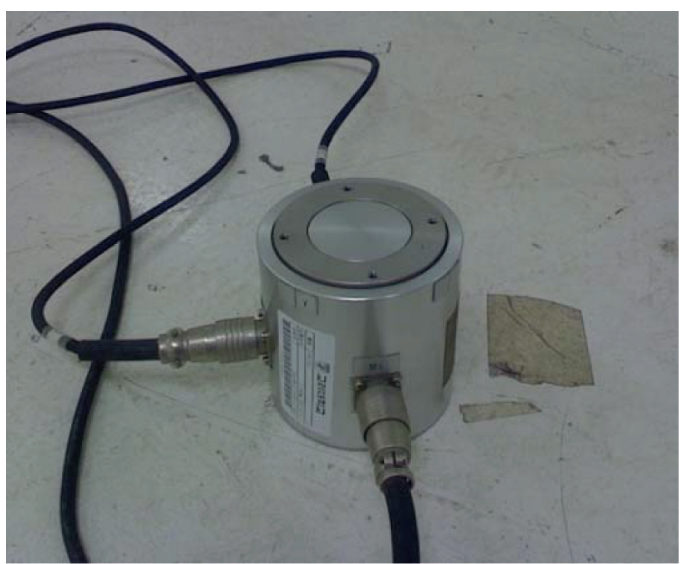

(a)

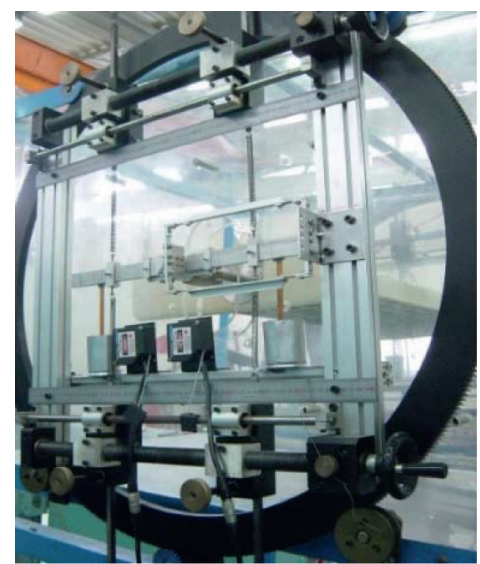

(b)

Figure 6: Test setup: (a) 3-component load cell for static test and (b) spring support system for dynamic test. From the measured forces, the static aerodynamic coefficients are calculated from

components load shown in Figure 6(a). For dynamic wind tunnel test, the spring support system shown in Figure 6(b) was used. The blockage ratio represents the ratio of projection area of the model to total area of $2 \mathrm{D}$ wind tunnel section. This ratio should be small enough (usually less than $5 \%$ ) so that the wind flow in $2 \mathrm{D}$ wind tunnel section is not affected by the test model. In this study, the blockage ratio was $3.64 \%$.

where $C_{d}$ is the aerodynamic drag force coefficient, $C_{l}$ is the aerodynamic lift force coefficient, $C_{m}$ is the aerodynamic moment coefficient, $F_{d}$ is the drag force, $F_{l}$ is the lift force, $F_{m}$ is the moment in the model, $\rho$ is the density of air, $U$ is the wind velocity, and $B$ is the reference length.

$$
\begin{aligned}
C_{d} & =\frac{F_{d}}{0.5 \rho U^{2} B}, \\
C_{l} & =\frac{F_{l}}{0.5 \rho U^{2} B}, \\
C_{m} & =\frac{F_{m}}{0.5 \rho U^{2} B^{2}} .
\end{aligned}
$$

Table 2 shows the static wind tunnel test cases. The test was conducted for both laminar and turbulent flows, where the turbulent intensity was $10 \%$. The maximum wind speed 
TABLE 2: Static wind tunnel test cases.

\begin{tabular}{lccc}
\hline & Flow type & Wind penetration ratio (\%) & Attack angle $\left(^{\circ}\right)$ \\
\hline & Laminar flow & 0 & 25 \\
Static test case & 50 & 0 & $-9,-6,-3,0,3,6,9$ \\
& Turbulent flow with intensity of $10 \%$ & 25 & 50 \\
\hline
\end{tabular}

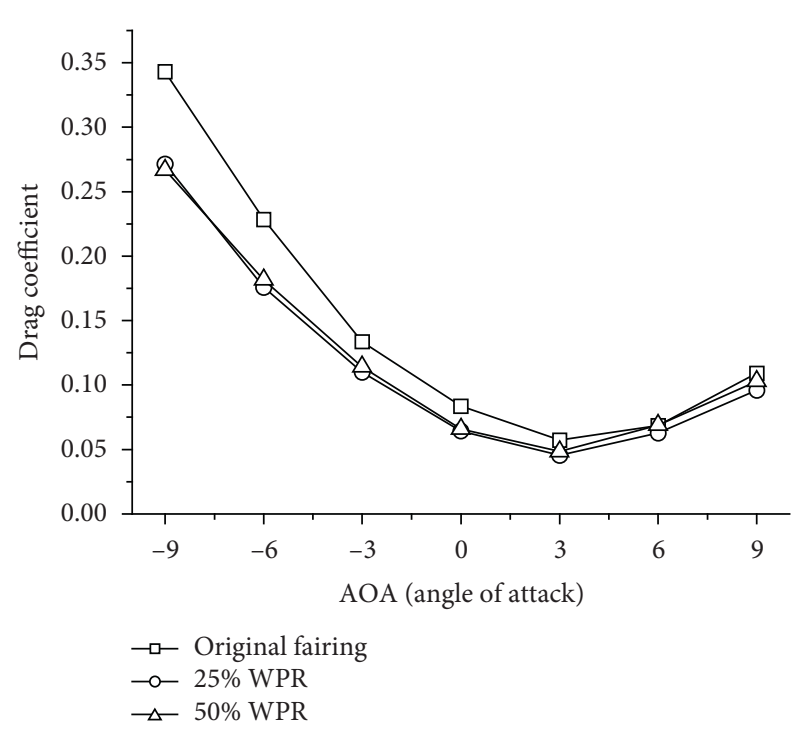

(a)

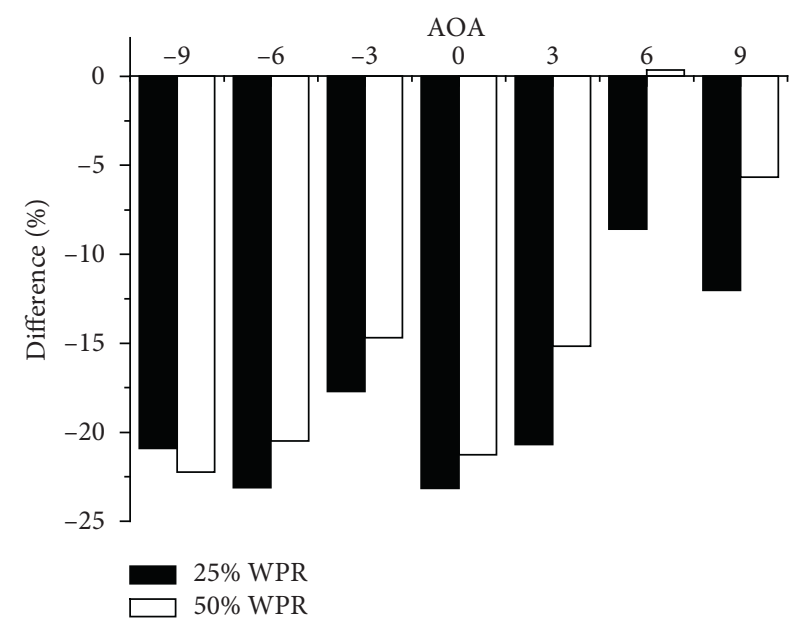

(b)

Figure 7: Static wind tunnel test results for $C_{d}$ (laminar flow): (a) $C_{d}$ versus AOA; (b) difference (\%) versus AOA.

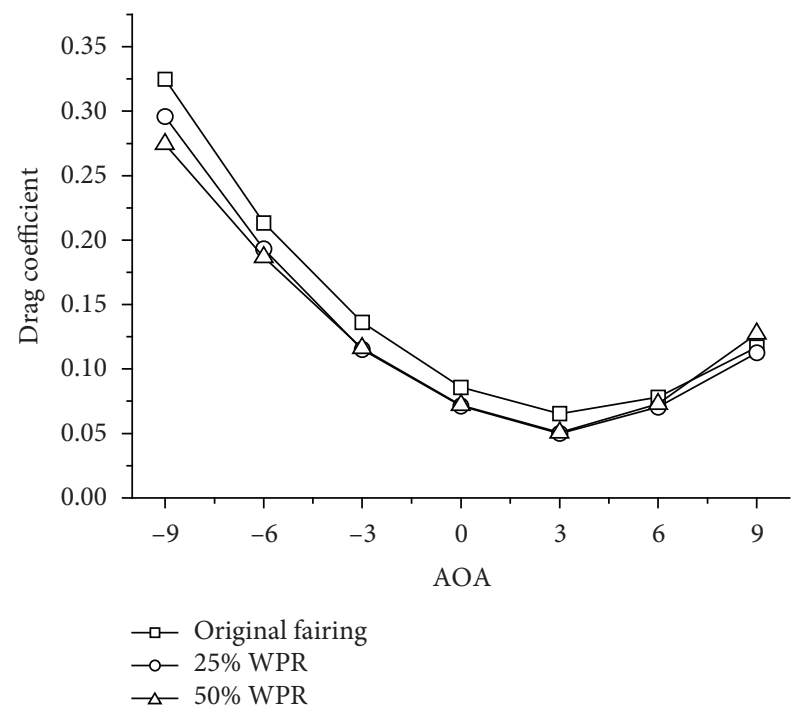

(a)

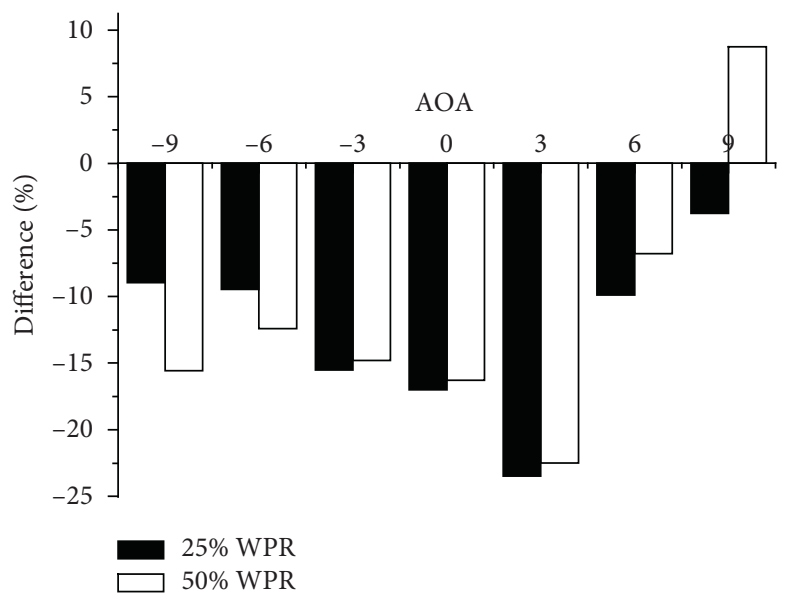

FIgURE 8: Static wind tunnel test results for $C_{d}$ (turbulent flow): (a) $C_{d}$ versus AOA; (b) difference (\%) versus AOA.

was $8 \mathrm{~m} / \mathrm{s}$, which is equivalent to the Reynolds number of $2.7 \times 10^{5}$. Three different WPRs of $0 \%, 25 \%$, and $50 \%$ and seven different angles of attack (AOA) from $-9^{\circ}$ to $9^{\circ}$ were considered in the test. A total of 42 cases were tested.
The dynamic wind tunnel test was also conducted to evaluate the dynamic stability of the bridge with proposed newtype hybrid fairing. The dynamic wind tunnel test was conducted by using the spring support system shown in Figure 6(b). Similar to the static wind tunnel test, laminar and 


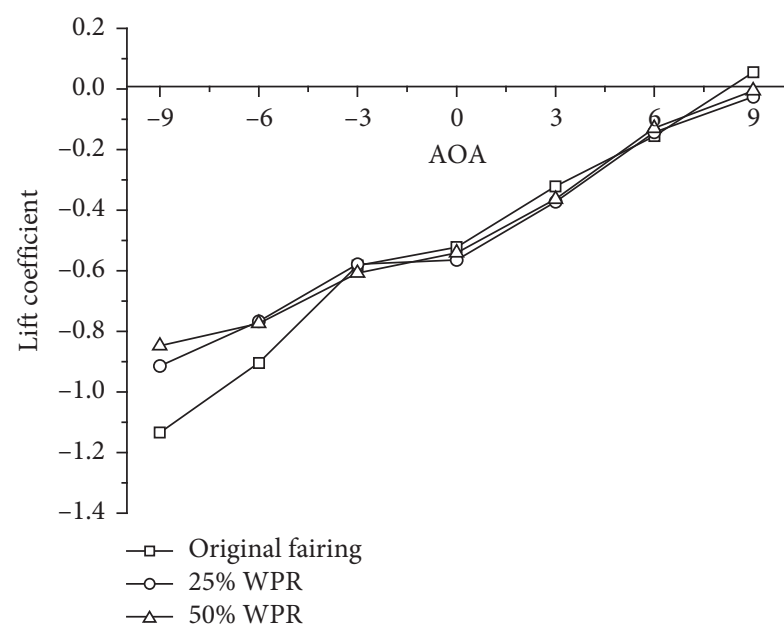

(a)

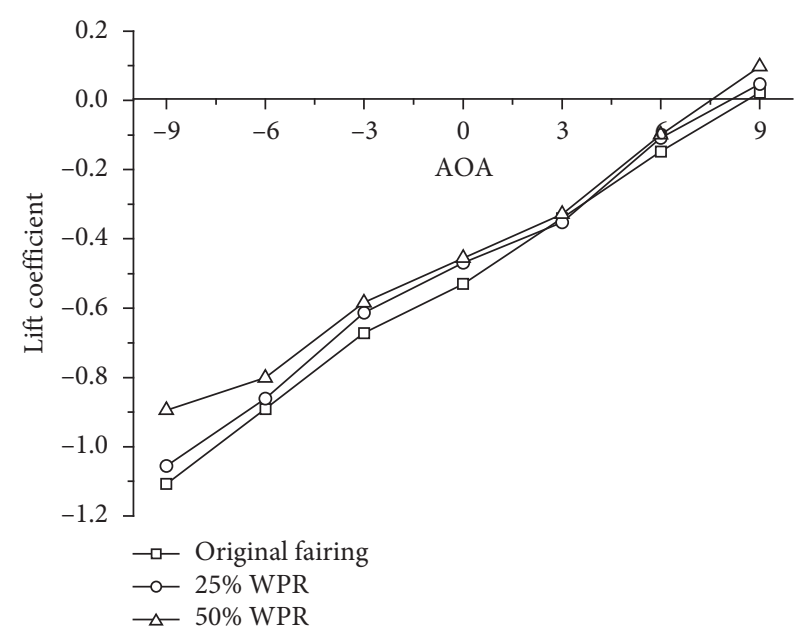

(b)

Figure 9: Static wind tunnel test results for $C_{l}$ : (a) laminar flow; (b) turbulent flow.

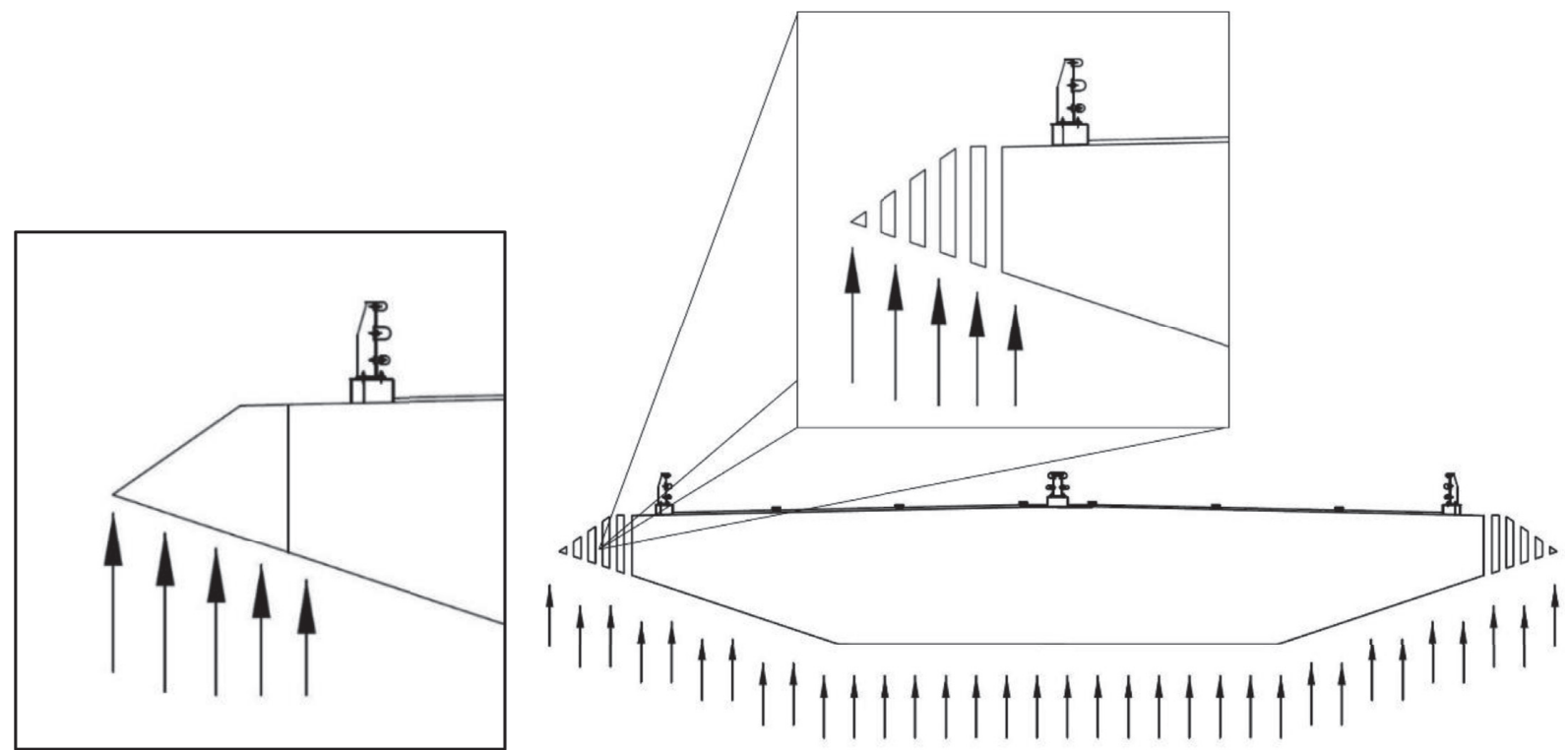

FIGURE 10: Schematic of the reduction of the lifting force resisting area by applying the proposed fairing.

turbulent flow with intensity of $10 \%$ were considered. Also, the same WPRs were used for the dynamic test. In the case of the angle of attack, three cases $\left(-3^{\circ}, 0^{\circ}\right.$, and $\left.3^{\circ}\right)$ were considered. Thus, a total of 18 cases are tested. Generally, AOA varies from $-3^{\circ}$ to $3^{\circ}$ in natural condition. Thus, in this study, the minimum and maximum $\mathrm{AOA}$ were considered with reference $\mathrm{AOA}$ $\left(=0^{\circ}\right)$ for the efficiency of the dynamic wind tunnel test.

\section{Test Results and Performance Evaluation of the Proposed Fairing}

4.1. Static Wind Tunnel Test Results. From the static wind tunnel test, the static aerodynamic coefficients $\left(C_{d}, C_{l}\right.$, and $C_{m}$ ) were extracted for each laminar and turbulent flow. Figure 7 shows the variation in $C_{d}$ with angle of attack (AOA) for the cases with the normal and new-type hybrid fairing.
From Figure 7(a), it can be seen that the cases with the proposed fairing have lower $C_{d}$ comparing with normal fairing for most AOA ranges. Figure 7 (b) shows the amount of $C_{d}$ reduction. The difference is calculated from $\left(C_{d}\right.$ of the proposed fairing- $C_{d}$ of the normal fairing) $/ C_{d}$ of the normal fairing (\%). In most cases, except for the case with AOA of $6^{\circ}$, the reduction of $C_{d}$ is larger than $10 \%$. In general, the practical range of $\mathrm{AOA}$ is varied from $-3^{\circ}$ to $3^{\circ}$. In this range, the $C_{d}$ reduction is approximately $15 \%$ to $23 \%$. This means that the static aerodynamic drag force can be reduced up to $15 \%-23 \%$ by applying the proposed new-type hybrid fairing. The winds pass through the void region of the proposed fairing. As a result, the wind acting on the bridge section is reduced compared to the case with the normal fairing. This leads to reduced $C_{d}$ for the case with the new-type hybrid fairing. Generally, except for the AOA of $-9^{\circ}$, PWR of $25 \%$ 


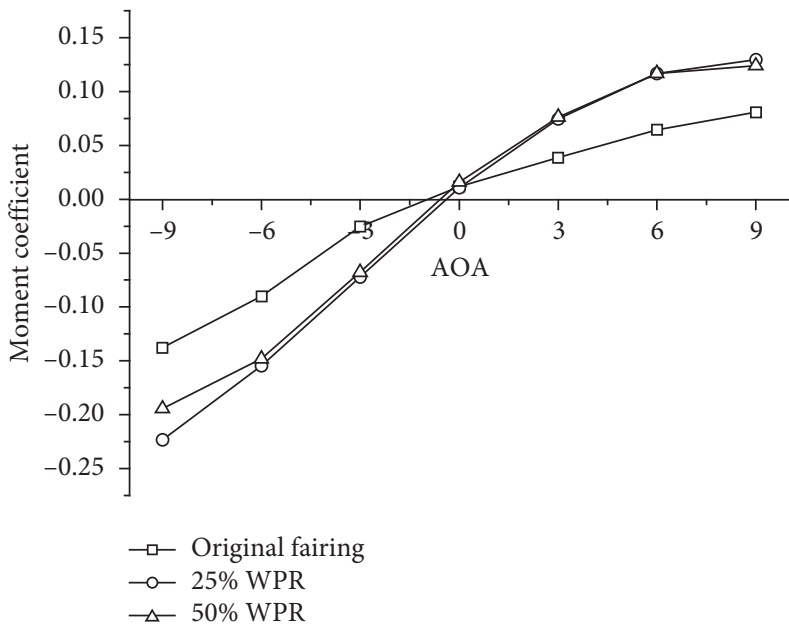

(a)

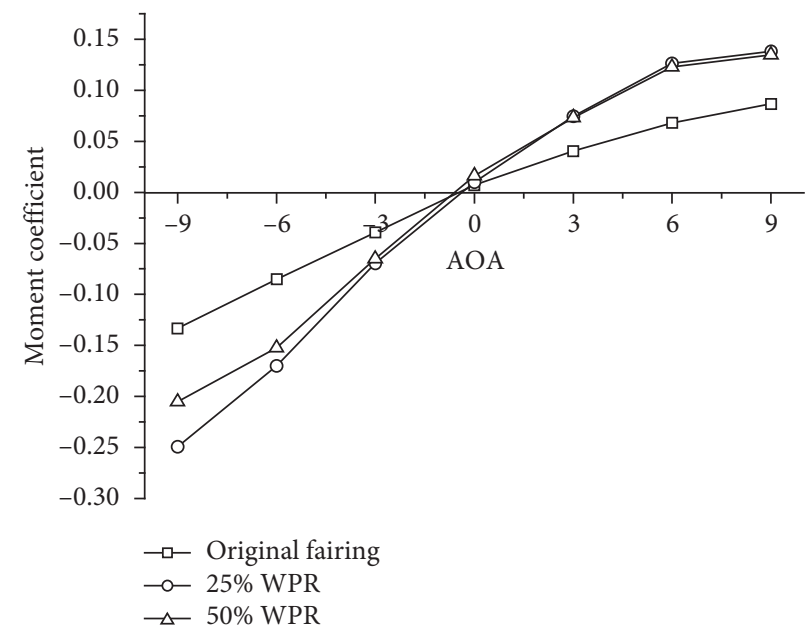

(b)

FIgURE 11: Static wind tunnel test results for $C_{m}$ : (a) laminar flow; (b) turbulent flow.

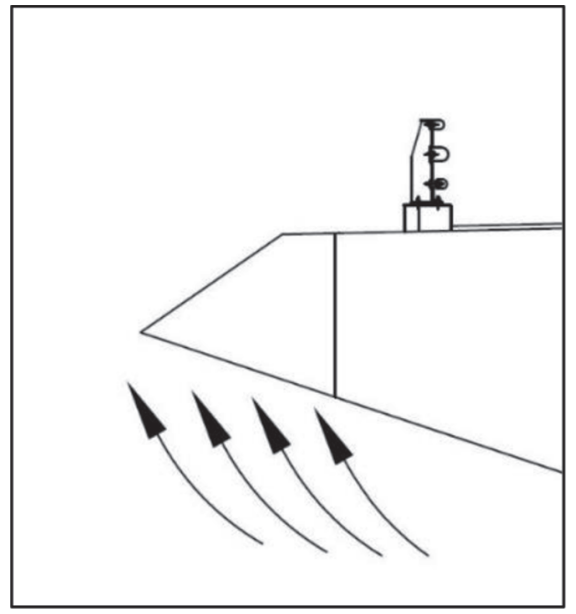

(a)

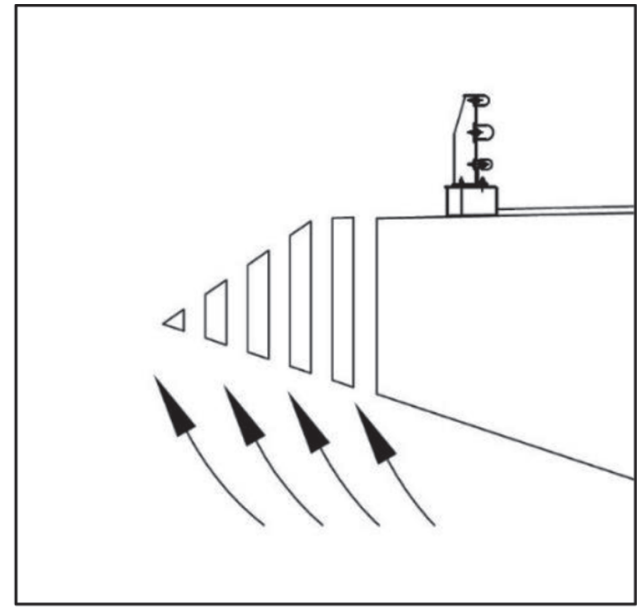

(b)

FIGURE 12: Schematic of the increase of wind resisting area for torsional moment by applying the proposed fairing.

shows better performance compared to WPR of $50 \%$, as shown in Figure 7(b).

Similar tests were conducted for turbulent flow condition and the results are shown in Figure 8. The overall trends of the test results are similar to those of the laminar flow condition. $C_{d}$ with the proposed fairing is lower than that with the normal fairing, as shown in Figures 8(a) and 8(b), except for the case with AOA of $9^{\circ}$. The effect of WPR on $C_{d}$ is not large, except for AOA of $\pm 9^{\circ}$. Similar to the laminar flow condition, $15 \%-23 \% C_{d}$ reduction compared to the case with the normal fairing was observed in the range of practical AOA (from $-3^{\circ}$ to $3^{\circ}$ ).

In summary, the proposed fairing shows lower $C_{d}$ compared to the normal fairing for both laminar and turbulent flow conditions.

Figures 9(a) and 9(b) show the variation in $C_{l}$ with AOA for the laminar flow and turbulent flow conditions, respectively. For the lower AOA region, such as $-9^{\circ}$ to $-6^{\circ}, C_{l}$ value with the proposed fairing is closer to 0 compared to the case with the normal fairing. This means that the proposed fairing can reduce the lifting force of the section. In the case of the practical AOA range from $-3^{\circ}$ to $3^{\circ}, C_{l}$ values are similar to each other for all the considered cases for laminar flow condition [refer to Figure 9(a)], while $C_{l}$ with the proposed fairing is slightly lower than that with the normal fairing for the turbulent flow condition [refer to Figure 9(b)]. By applying the proposed fairing, it is expected that the wind resisting area of the fairing will be reduced. However, it should be noted that most of the lifting force is applied to the bottom of the main section, and the area of the fairing is not large compared to the bottom area of the section, as shown in Figure 10. Thus, in the practical range of AOA, the reduction in $C_{l}$ by applying the proposed fairing is small.

Figures 11(a) and 11(b) show the variations in $C_{m}$ with AOA for laminar and turbulent flow condition, respectively. For all considered AOA, the proposed fairing shows larger 


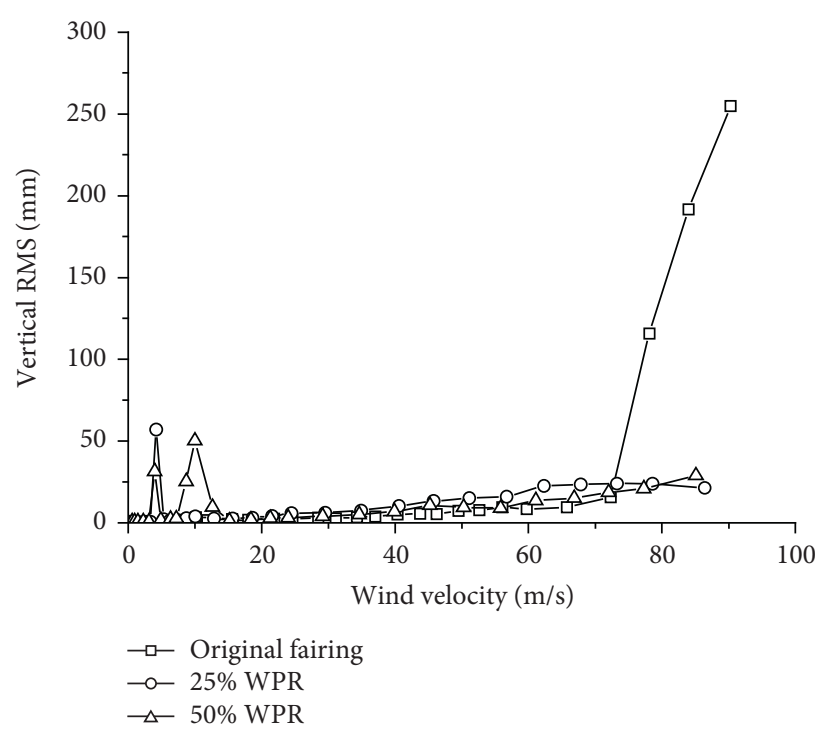

(a)

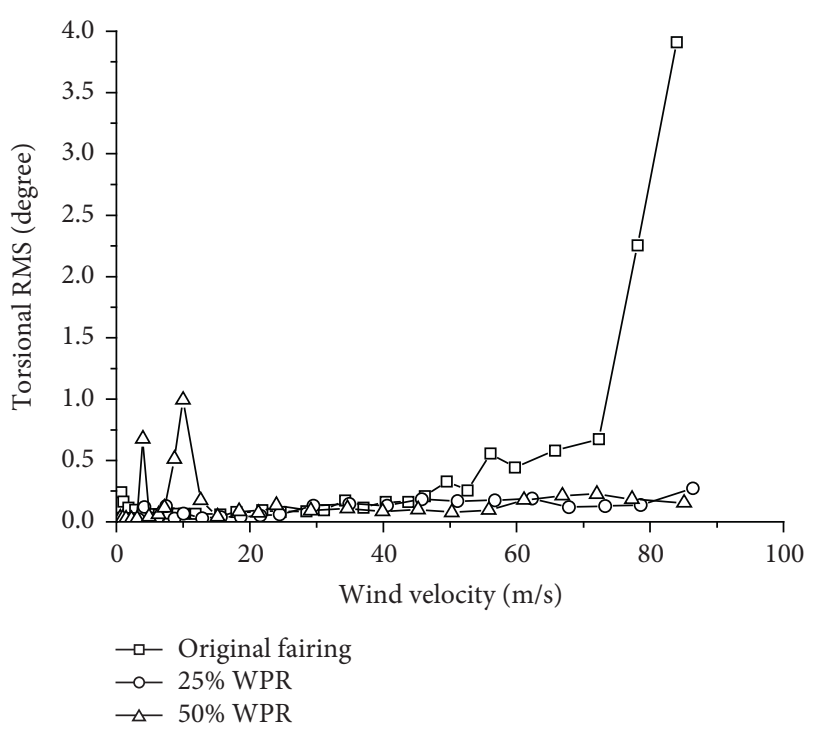

(b)

FIGURE 13: RMS versus wind velocity in laminar flow (attack angle $-3^{\circ}$ ): (a) vertical RMS; (b) torsional RMS.

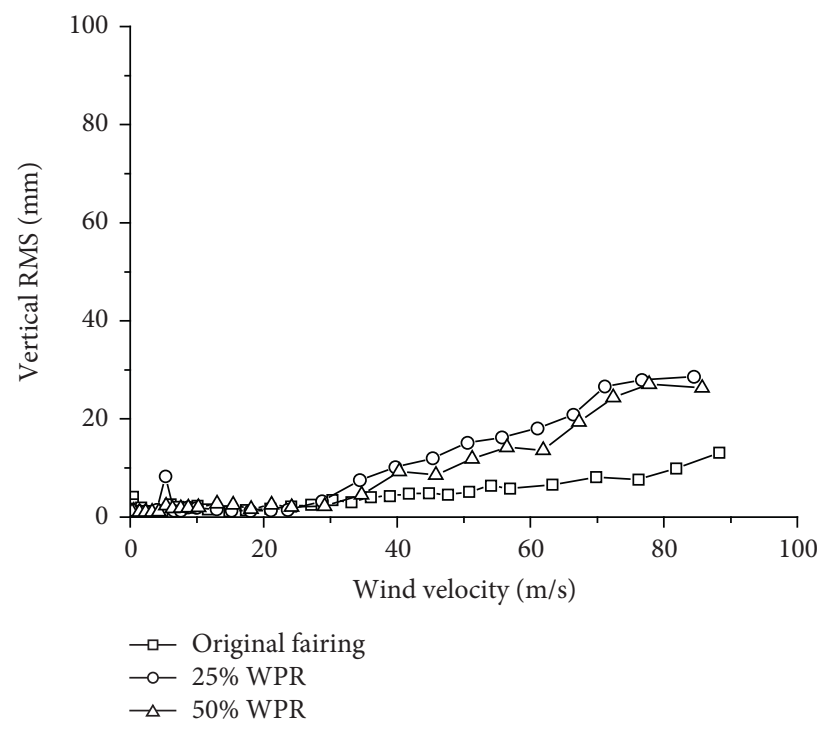

(a)

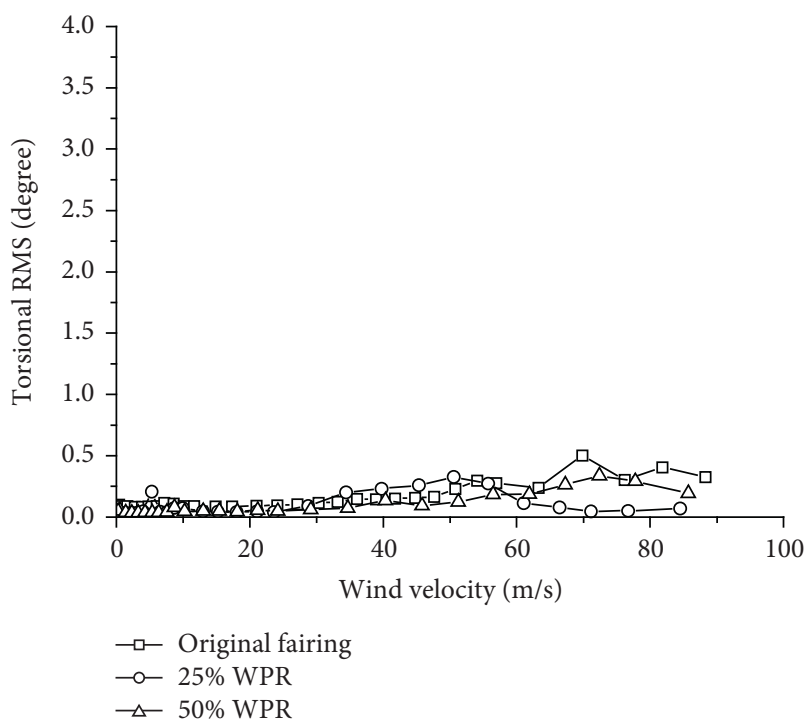

(b)

FIGURE 14: RMS versus wind velocity in laminar flow (attack angle $0^{\circ}$ ): (a) vertical RMS; (b) torsional RMS.

absolute values of $C_{m}$ compared to the normal fairing. Thus, the larger torsional moment to the section is expected when the proposed fairing is used, and the normal fairing shows better performance. Figure 12 shows a schematic of the wind flows for the torsion of the section. From Figure 12, it can be seen that the proposed fairing increases the wind resisting area due to the walls in the fairing. This results in increased $C_{m}$ for the proposed fairing comparing to the normal fairing.

In summary, for the practical range of AOA, it can be found that the proposed fairing can reduce the drag force of the section, while increasing the torsional moment. The lifting forces are similar to each other for the cases with the normal and proposed fairing.
4.2. Dynamic Wind Tunnel Test Results. The dynamic wind tunnel test was conducted for the section with the normal and proposed fairing for the practical range of AOA of from $-3^{\circ}$ to $3^{\circ}$ and both laminar and turbulent flow conditions. Figures 13-15 represent the dynamic wind tunnel test results for laminar flow condition with $-3^{\circ}, 0^{\circ}$, and $3^{\circ} \mathrm{AOA}$, respectively.

In Figures 13-15, the $x$-axis is the wind velocity, and the $y$-axis denotes the RMS value for vertical displacement or rotation angle. For AOA of $-3^{\circ}$, when the normal fairing is used, the flutter was observed for both vertical and rotational directions, as shown in Figures 13(a) and 13(b), while for the proposed fairing, flutter does not occur. However, when the 


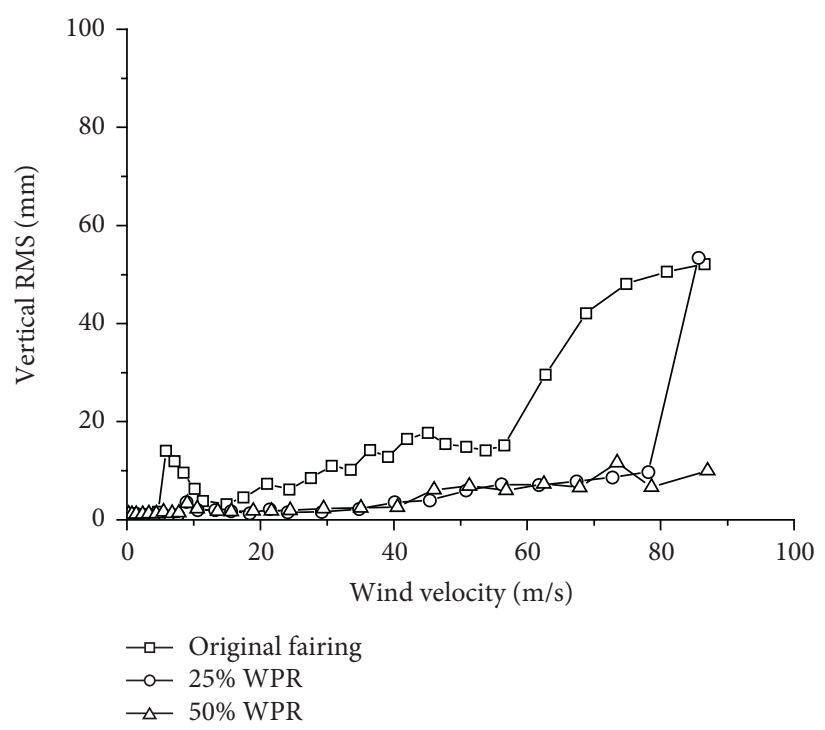

(a)

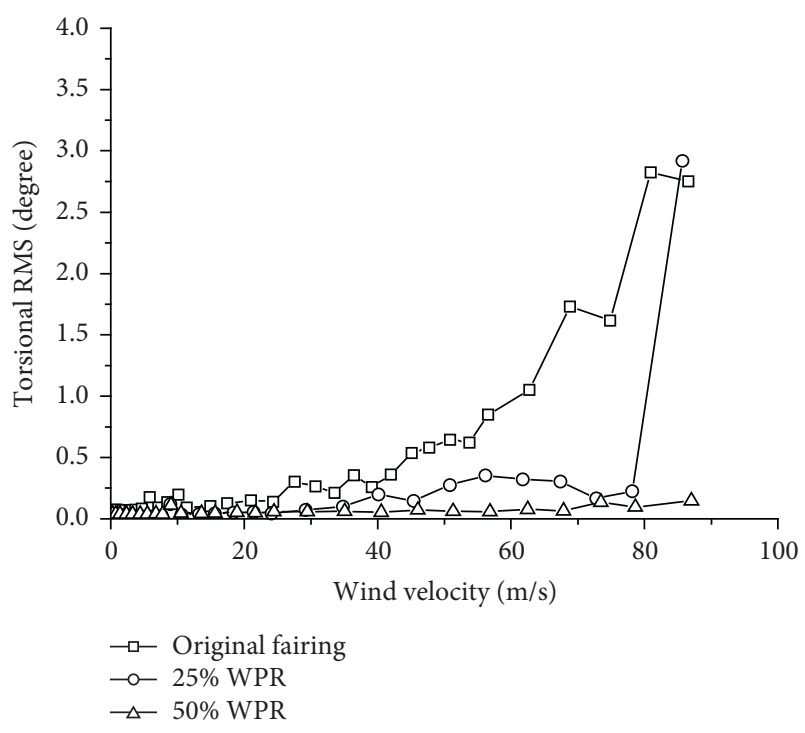

(b)

FIGURE 15: RMS versus wind velocity in laminar flow (attack angle $3^{\circ}$ ): (a) vertical RMS; (b) torsional RMS.

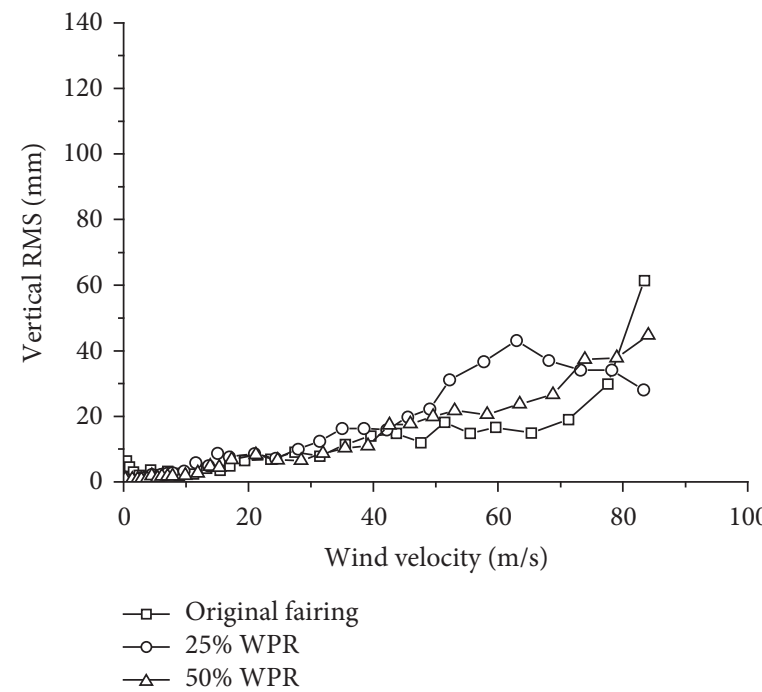

(a)

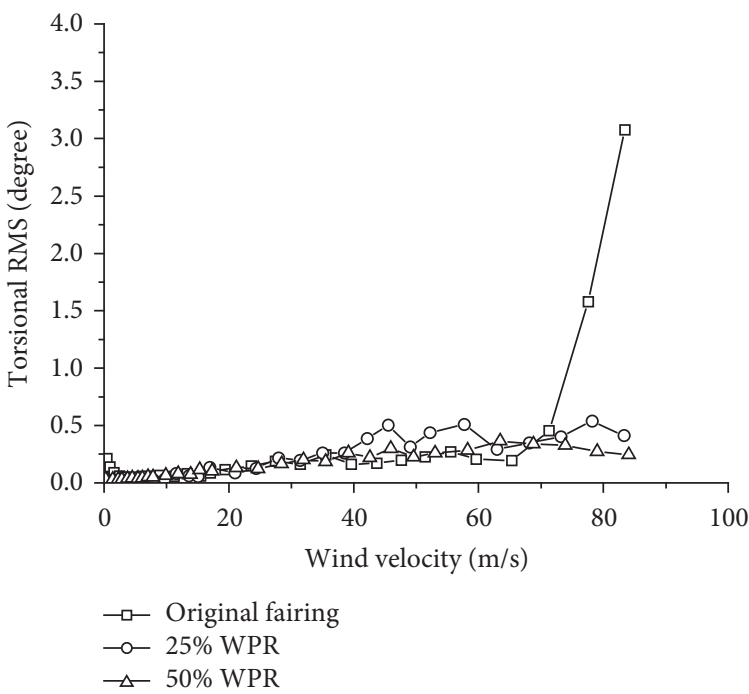

(b)

FiguRE 16: RMS versus wind velocity in turbulent flow (attack angle $-3^{\circ}$ ): (a) vertical RMS; (b) torsional RMS.

proposed fairing is used, larger vortex-induced vibration was observed. From the results, the flutter speed was $78.1 \mathrm{~m} / \mathrm{s}$ for both the vertical and torsional directions.

When AOA is $0^{\circ}$ [refer to Figures 14(a) and 14(b)], flutter behavior was not noted during the test for all cases. The vortex-induced vibration was observed for the case with $\mathrm{WPR}=25 \%$ around wind velocity of $5.3 \mathrm{~m} / \mathrm{s}$. The larger vertical displacements occurred with increasing wind velocity for the case with the proposed fairing. In the case of torsion, torsional behaviors are similar to each other for all cases, except the vortex-induced vibration for the 25\% WPR case.

Figure 15 shows the test results for AOA of $3^{\circ}$. For the case with normal fairing, both the vortex-induced vibration and flutter occurred. Flutter was also observed for the case with the WPR of $25 \%$. The flutter speed of the case with the normal fairing was $68.8 \mathrm{~m} / \mathrm{s}$ for vertical and torsional directions. In the case of WPR of $25 \%$, the flutter speed was $85.7 \mathrm{~m} / \mathrm{s}$ for the vertical and torsional directions. Thus, it can be seen that the proposed fairing increases the flutter speed even if flutter occurs. When WPR is $50 \%$, there is no vortexinduced vibration and flutter from the dynamic test with laminar flow condition.

Similar to the laminar flow condition, the dynamic wind tunnel test was conducted for the turbulent flow with intensity of $10 \%$. In turbulent flow, both the magnitude and direction of the wind flow are continuously changed. Thus, overall RMS response in turbulent flow is usually lager than that of laminar flow. Also, vortex-induced vibration is 


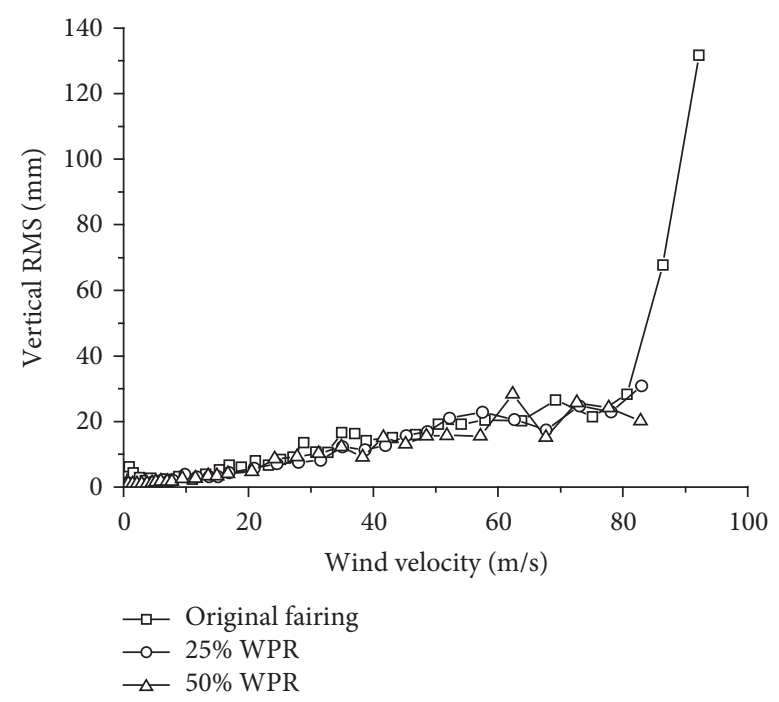

(a)

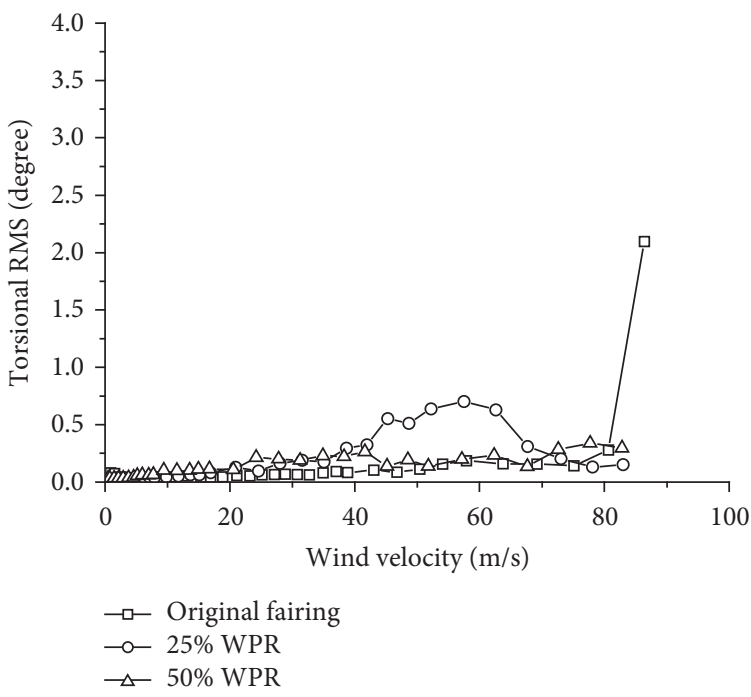

(b)

FigURE 17: RMS versus wind velocity in turbulent flow (attack angle $0^{\circ}$ ): (a) vertical RMS; (b) torsional RMS.

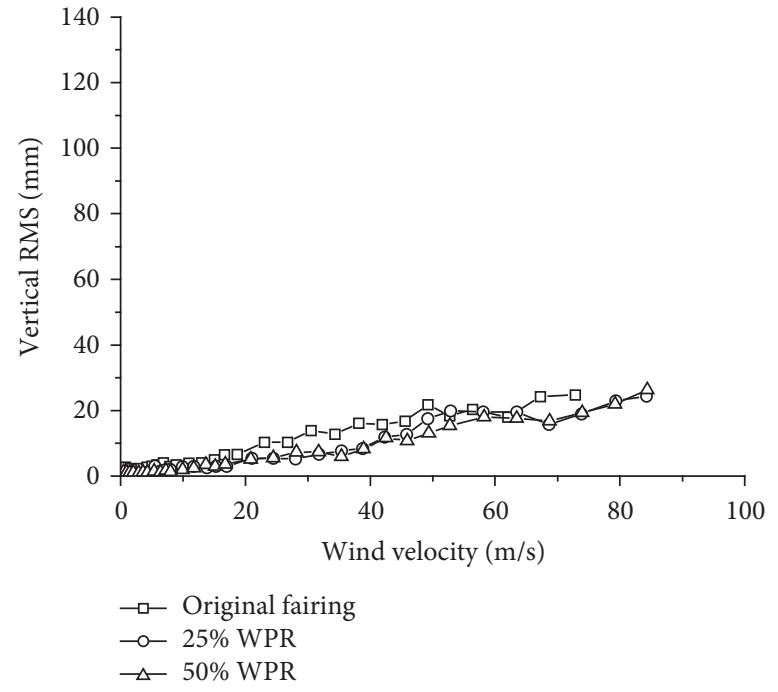

(a)

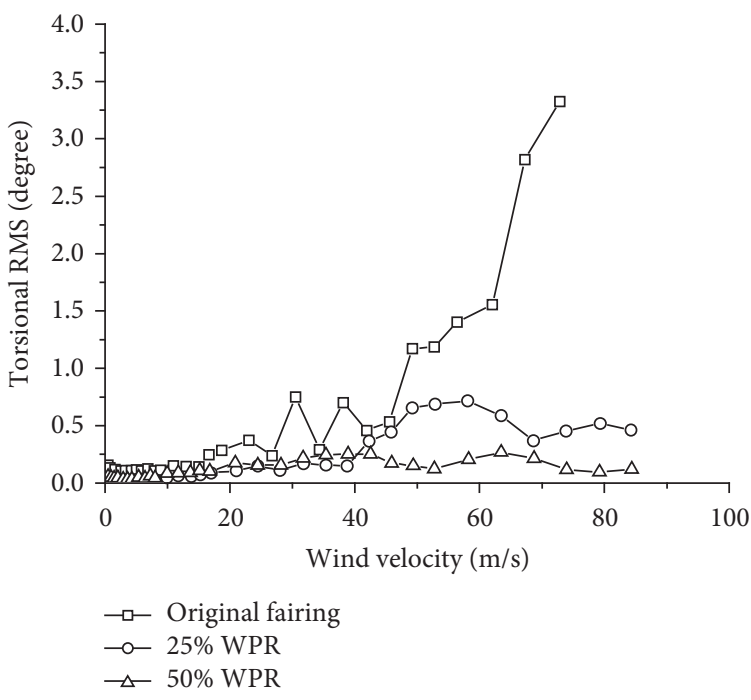

(b)

FIGURE 18: RMS versus wind velocity in turbulent flow (attack angle $3^{\circ}$ ): (a) vertical RMS; (b) torsional RMS.

reduced in turbulent flow comparing to the case with laminar wind flow since the turbulent flow contains many different-frequency components of the wind. The vortexinduced vibration occurs when the vortex shedding and the structural vibration synchronize at common frequency. Similar behaviors were observed for the dynamic test conducted in this study.

Figures 16-18 show the dynamic test results. When AOA is $-3^{\circ}$ and $3^{\circ}$, the torsional flutter occurs for the case with the normal fairing, as shown in Figures 16(b) and 18(b), respectively. For AOA of $0^{\circ}$, when the normal fairing is applied, both vertical and torsional flutter were observed, as shown in Figures 17(a) and 17(b). However, when the proposed fairing is used, there were no considerable instabilities. The flutter did not occur with the wind velocity considered. From the dynamic test results, it can be found that the proposed new-type hybrid fairing shows better flutter resistance comparing with the section with the normal fairing. In some cases, especially for laminar flow condition, large vortex-induced vibration occurred. This vortex-induced vibration is often observed in the multibox section [19], and similar behavior occurs in the proposed new-type hybrid fairing.

\section{Conclusions}

This study proposes the concept of a new-type hybrid fairing. To improve the aerodynamic performance of the normal fairing, the concept of the multibox section is applied. Then, the aerodynamic characteristics of the proposed fairing are 
evaluated from a series of wind tunnel tests. From the wind tunnel test, the major findings are as follows:

(1) From the static wind tunnel test, it can be found that the proposed fairing shows lower $C_{d}$ comparing with the normal fairing for both laminar and turbulent flow conditions in the practical range of AOA of $-3^{\circ}$ to $3^{\circ}$. This is because the wind passes through the gaps in the fairing, and the wind acting on the bridge section decreases. Thus, by applying the proposed fairing, reduction in drag force is expected.

(2) In the case of $C_{l}$, the effect of the proposed fairing is negligible for the practical range of AOA. Also, by applying the proposed fairing, $C_{m}$ is increased due to the increase of the wind resisting area. Thus, when the proposed fairing is applied, the torsional behavior should be carefully examined.

(3) From the dynamic wind tunnel test, it can be seen that the proposed fairing improves the flutter resistance for all the considered cases. Thus, the use of the proposed fairing is an effective way to increase the flutter speed of the long-span cable-stayed bridge. However, in some cases, large vortex-induced vibration is observed. This vortex-induced vibration should be carefully considered when the proposed fairing is used.

\section{Data Availability}

The data used to support the findings of this study are available from the corresponding author upon request.

\section{Conflicts of Interest}

The authors declare that they have no conflicts of interest.

\section{Acknowledgments}

This work was funded by the Korea Electric Power Corporation (KEPCO).

\section{References}

[1] M. Matsumoto, H. Shirato, and T. Yagi, "Recent topics on bridge aerodynamics," Wind and Structures, vol. 3, no. 4, pp. 267-277, 2000.

[2] Y. Fujuno, "Vibration, control and monitoring of long-span bridges-recent research, development and practice in Japan," Journal of Constructional Steel Research, vol. 58, pp. 71-97, 2002.

[3] A. Larsen and A. Wall, "Shaping of bridge box girders to avoid vortex shedding response," Journal of Wind Engineering \& Industrial Aerodynamics, vol. 104-106, pp. 156-165, 2012.

[4] D. Fransos and L. Bruno, "Edge degree-of-sharpness and freestream turbulence scale effects on the aerodynamics of a bridge deck," Journal of Wind Engineering and Industrial Aerodynamics, vol. 98, no. 10-11, pp. 661-671, 2010.

[5] H. Lee, J. Moon, N. Chun, and H. E. Lee, "Effect of beam slope on the static aerodynamic response of edge-girder bridgedeck," Wind and Structures, vol. 25, no. 2, pp. 157-176, 2017.
[6] Y. Daito, M. Matsumoto, and K. Araki, "Torsional flutter mechanism of two-edge girders for long-span cable-stayed bridge," Journal of Wind Engineering and Industrial Aerodynamics, vol. 90, no. 12-15, pp. 2127-2141, 2002.

[7] Y. Sakai, K. Ogawa, H. Shimodoi, and T. Saitoh, "An experimental study on aerodynamic improvements for edge girder bridges," Journal of Wind Engineering and Industrial Aerodynamics, vol. 49, no. 1-3, pp. 459-466, 1993.

[8] F. Nagao, H. Utsunomiya, T. Oryu, and S. Manabe, "Aerodynamic efficiency of triangular fairing on box girder bridge," Journal of Wind Engineering and Industrial Aerodynamics, vol. 49, no. 1-3, pp. 565-574, 1993.

[9] Sukamta, F. Nagao, M. Noda, and K. Muneta, "Aerodynamic stability of suramadu cable stayed bridge," Journal of Structural Engineering, vol. 54A, pp. 429-435, 2008.

[10] M. N. Haque, H. Katsuchi, H. Yamada, and M. Nishio, "Investigation of edge fairing shaping effects on aerodynamic response of long-span bridge deck by unsteady RANS," Archives of Civil and Mechanical Engineering, vol. 16, no. 4, pp. 888-900, 2016.

[11] T. Tanaka, T. Yoshimura, N. J. Gimsing et al., "A study on improving the design of hybrid stress-ribbon bridges and their aerodynamic stability," Journal of Wind Engineering and Industrial Aerodynamics, vol. 90, no. 12-15, pp. 1995-2006, 2002.

[12] F. Brancaleoni and G. Diana, "The aerodynamic design of the Messina Straits bridge," Journal of Wind Engineering and Industrial Aerodynamics, vol. 48, no. 2-3, pp. 395-409, 1993.

[13] M. Matsumoto, K. Mizuno, K. Okubo, and Y. Ito, “Torsional flutter and branch characteristics for 2-D rectangular cylinders," Journal of Fluids and Structures, vol. 21, no. 5-7, pp. 597-608, 2005.

[14] H. Sato, S. Kusuhara, K.-I. Ogi, and H. Matsufuji, "Aerodynamic characteristics of super long-span bridges with slotted box girder," Journal of Wind Engineering and Industrial Aerodynamics, vol. 88, no. 2-3, pp. 297-306, 2000.

[15] S. Shirai and T. Ueda, "Aerodynamic simulation by CFD on flat box girder of super-long-span suspension bridge," Journal of Wind Engineering and Industrial Aerodynamics, vol. 91, no. 1-2, pp. 279-290, 2003.

[16] S. Watanabe, H. Inoue, and K. Fumoto, "An estimation of static aerodynamic forces of box girders using computational fluid dynamics," Wind and Structures, vol. 7, no. 1, pp. 29-40, 2004.

[17] A. Larsen, M. Savage, A. Lafrenière, M. C. H. Hui, and S. V. Larsen, "Investigation of vortex response of a twin box bridge section at high and low Reynolds numbers," Journal of Wind Engineering and Industrial Aerodynamics, vol. 96, no. 6-7, pp. 934-944, 2008.

[18] H. Li, S. Laima, J. Ou et al., "Investigation of vortex-induced vibration of a suspension bridge with two separated steel box girders based on field measurements," Engineering Structures, vol. 33, no. 6, pp. 1894-1907, 2011.

[19] G. Diana and G. Fiammenghi, "Wind tunnel tests and numerical approach for long span bridges: the Messina bridge," Journal of Wind Engineering and Industrial Aerodynamics, vol. 122, pp. 80-103, Shanghai, China, 2012.

[20] Z. Wang and E. Dragomirescu, "Flutter derivatives identification and aerodynamic performance of an optimized multibox bridge deck," Advances in Civil Engineering, vol. 2016, Article ID 8530154, 13 pages, 2016.

[21] A. Zasso, T. Argentini, I. Bayati, M. Belloli, and D. Rocchi, "Super-long bridges with floating towers: the role of multi-box decks and Hardware-In-the-Loop technology for wind tunnel 
tests," Materials Science and Engineering, vol. 276, pp. 1-11, 2017.

[22] K. Li, Y. J. Ge, Z. W. Guo, and L. Zhao, "Theoretical framework of feedback aerodynamic control of flutter oscillation for long-span suspension bridges by the twin-winglet system," Journal of Wind Engineering and Industrial Aerodynamics, vol. 145, pp. 166-177, 2015.

[23] K. Gouder, X. Zhao, D. Limebeer, and M. R. Graham, "Experimental flutter suppression of a long-span suspension bridge section," First International Symposium on Flutter and Its Application, vol. 41, no. 4, pp. 362-369, 2016. 